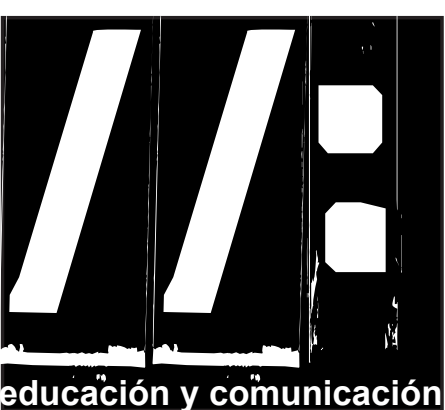

3: 111-118 Nov. 2011

\section{PRÁCTICA POLÍTICA Y NOSTALGIA: CINE Y HOMOSEXUALIDAD EN DEREK JARMAN Y PIER PAOLO PASOLINI}

\section{Political practicea and nostalgia: Derek Jarman; Pier Paolo Pasolini; subversión and cinema; cinema and homosexuality.}

\author{
Ana Sedeño Valdellós \\ Universidad de Málaga \\ E-mail: valdellos@uma.es
}

Resumen:

Derek Jarman y Pier Paolo Pasolini se merecen un lugar especial en la historia del cine. Abiertamente homosexuales, su obra fílmica tiene en común un vínculo voluntario y nostálgico con la historia y con el pasado. La herencia de la época isabelina, en el caso de Jarman, y del pasado clásico y el mito en el de Pasolini fructifica en fórmulas subversivas que tienen el valor de contravenir las estructuras narrativas convencionales huyendo de los propios tópicos del cine de autoría homosexual.

Palabras clave: Derek Jarman; Pier Paolo Pasolini; subversión y cine; cine y homosexualidad.

\title{
Abstract:
}

Derek Jarman and Pier Paolo Pasolini deserve a special place in the history of cinema. Open homosexuals, their opus displays a common thread of nostalgia that explores history and the past; in the case of Jarman, we can talk about the inheritance from the Elizabethan era, while Pasolini is influenced by the classics and western mythology. Both use subversive techniques to write against conventional narrative structures and distance themselves from the stereotypes reproduced by other homosexual directors.

Key words: Derek Jarman; Pier Pasolini; subversion and cinema; cinema and homosexuality. 


\section{Introducción}

L a sexualidad se ha convertido en un terreno preferente para desarrollar debates en torno a la construcción ideológica y social de los individuos, y en un discurso que permite conectar lo biológico con lo cultural y experiencial y articula fórmulas de identidad y de mediación entre la realidad y el imaginario personal.

El cine, parte del conjunto de aparatos ideológicos del Estado, cumple una función de reproducción de ideologías mediante su poder de creación y consolidación de determinados imaginarios. De la misma manera, su capacidad para representar opciones subversivas y de oposición política a un orden normativo se ha demostrado en múltiples ocasiones y épocas. El cine, una tecnología de género, formaliza un discurso que construye identidades personales y colectivas alrededor de conceptos tan importantes como relaciones sociales, intimidad, cuerpo...

Lejos de la simplista afirmación de que todo cine es político, es cierto que su ilustración presenta líneas históricas básicas. Por un lado, se encuentra la que ha llegado desde el constructivismo y el formalismo soviético, alargado a buena parte del documental, sobre todo en Latinoamérica, y, por otro, la vertiente realista, que aterrizó en el cine después de la posguerra. Existe, sin embargo, otra rama no siempre visible, la relacionada con lo queer, nacida de la revolución cultural de finales de los sesenta y conectada con ciertas prácticas del arte contemporáneo de la época, el happening, el teatro nuevo, el pop... Desde siempre, el público LGTB (Lesbianas, Gays, Transexuales y Bisexuales) ha buscado en las manifestaciones culturales modelos de comportamiento y vida. Necesitados de autoafirmación en la consolidación de actitudes y elecciones sexuales y emocionales, esta audiencia ha tendido a localizar en literatura, pintura o música ejemplos positivos (bien en la representación, bien en la autoría) en los que fijarse. El cine, arte visual relacionado con la representación analógica del mundo y medio de creación fuertemente ligado a la cultura popular, no podía quedarse fuera de esta lista. Como demuestra el documental de found footage El celuloide oculto (1995), el terreno de la serie B, las producciones independientes en los márgenes de la industria y el cine amateur y de autor guarda inagotables ejemplos de escenas con esta temática. Con el exitoso ascenso del cine independiente y underground y ayudado por la revolución cultural y la emergencia de los llamados nuevos cines, el fenómeno cuajó en movimiento, en tendencia. El término new queer cinema fue utilizado por primera vez en la revista británica Sight and Sound por B. Rudy Rich en 1992. Sobre la base de la teoría postestructuralista y postmodernista toma al individuo como una construcción social en sus diferentes aspectos o facetas, incluida la sexual.

Su posición marginal ha eclipsado las numerosas perspectivas y matices de algunos directores que, explícitamente homosexuales, han interpretado sus historias desde esta sensibilidad, pero cuyo cine es absolutamente personal, difícilmente encasillable. Comenzamos aquí un recorrido que trata de reflexionar sobre la obra de dos directores homosexuales. Derek Jarman y Pier Paolo Pasolini fueron creadores de un discurso que mezclaba una práctica política en la que la homosexualidad se constituía como eje vertebral de una concepción revolucionaria de la vida social y del arte, con un posicionamiento que podríamos situar cercano a una cierta idea de nostalgia. 
Práctica política y nostalgia: Cine y homosexualidad en Derek Jarman y Pier Paolo Pasolini

\section{Derek Jarman: flores y sonidos}

El pintor y cineasta británico Derek Jarman (Northwood, Inglaterra, 1942) es una figura notable en la lucha por los derechos de los homosexuales en Gran Bretaña. Hijo de un militar y una modista vivió los primeros años de su vida de viaje constante, a causa del trabajo de su padre, lo que le permitió conocer gran parte del legado artístico europeo. Estudió en el internado Houdle House, en Milford on Sea, donde comenzó a pintar como forma de huir de la dura represión de la institución. Durante su juventud gozó de la vida underground de Londres, vivió la etapa liberalista y represora de la Gran Bretaña de Margaret Thatcher y conoció a múltiples personalidades de la movida musical y artística nacional de los años setenta y ochenta.

En su libro At your Own Risk (1992), comenta su vida como marcada por una sexualidad escondida o criminalizada. Sin embargo, su postura política nos describe una práctica cinematográfica lejana a la culpa y reconocidamente militante, que emplea su homosexualidad como un arma contra el orden establecido. La visión de Jarman sobre la historia y sobre el arte es activista. En un contexto de "cine de la herencia", como Andrew Higson llama al período de cine británico desde principios de los ochenta a algo menos de la mitad de los noventa, Jarman se aleja del mainstream narrativo para desplegar un cine más cercano a lo queer.

«'Heterosoc' es el término que Jarman asignó a la dominación sistemática de la subcultura queer por la mayoría hetero-opresiva que controla las oficinas

\section{Divulgatio}

del Estado y las instituciones de la sociedad civil. Lo 'Heterosoc' emerge como un componente sexual dentro de un cerco hegemónico de ímpetus de la homogeneidad social y política, y promulga su ascendencia relativamente insignificante para la clase atomística, étnica, generacional, genérica o de intereses regionales. Aunque avanza en una ideología de libertad individual, particularmente en el dominio privado del consenso de relaciones adultas, 'Heterosoc' es, de hecho, predicado en una estricta, incuestionable adherencia a las concepciones naturalizadas del lícito deseo y afección heterosexual» (Meyler, 1996: 119; traducción Rodríguez, 2011).

Aunque con referencia a estos aspectos en la mayoría de sus películas, son Sebastián (1975), Eduardo II (1991) y Caravaggio (1986) las que afrontan directamente una postura de reivindicación de figuras históricas homosexuales. Sebastián se estrenó en el Festival de Cine de Locarno en 1975 y tuvo notable éxito en Inglaterra y España. Película difícil, hablada en latín, tiene referencias directas a la trilogía de la vida de Pasolini, especialmente a Los cuentos de Canterbury (1972).

Un aspecto destacable de sus tratamientos artísticos tiene que ver con la conceptualización y abstracción de escenografías y puestas en escena. En algunas de sus películas, Jarman emplea recursos contradictorios entre componentes de la puesta en escena que hacen desdibujar el contexto directo de la acción referida. En Eduardo II (1991), el rey y su amante visten modernos trajes italianos, sin embargo, la escenografía describe detalladamente la corte del rey. Tenemos aquí un pasado y un presente revisitados uno desde el otro, interpretados y fundidos en una misma acción. Una variante de esta idea es la abolición de lo escenográfi- 
co, presente en Caravaggio (1986), Eduardo II (1991) y Wittgenstein (1993). En esta última, los personajes aparecen sobre un fondo neutro negro, acentuando así la abstracción del propio pensamiento del filósofo. Como señala Nick Clapson, Jarman no está interesado en ahondar en el personaje, sino en que represente a un grupo social, en su capacidad de conversión en icono, y en lograr que esta transposición se articule con objetivos políticos en el film (Rodríguez, 2011). El retorno al pasado parece que se convirtió para Jarman en un reclamo para la construcción de una subjetividad queer en su presente. Por un lado, la referencia constante a Shakespeare, Piers Plowman, Chaucer y Marlowe y al período isabelino, que conoció en su adolescencia en clases complementarias de su internado. Por otro lado, retoma el renacimiento como guía para fijarse en las prácticas de la filosofía hermética y la alquimia, practicantes, para él, de un arte esotérico bajo constante persecución. John Dee (astrólogo, matemático y filósofo inglés que tuvo importante influencia en la política isabelina) produjo la máxima fascinación en el director, apareciendo de alguna forma en Jubilee (1977), The Tempest (1980) y The Angelic Conversation (1985). Marsilius Ficini, Cornelius Agrippa, Pico Della Mirandola o Giordano Bruno son creadores renacentistas que aparecen en variados textos de Jarman. La creencia en el poder de las imágenes está en el corazón del sistema de la memoria, construido por Giordano Bruno, para quien "el arte clásico de la memoria... se ha convertido en el vehículo para la formación de la pshyche de un místico hermético y mago. El principio hermético de la reflexión del universo en la mente como una experiencia religiosa se organiza a través del arte de la memoria en una técnica mágico-religiosa para aprehender y unificar el mundo de la apariencia a través de la disposición de imágenes significativas" (Yates, 1966: 229). Parte de la apropiación directa de Jarman respecto al sistema icónico del hermetismo son las flores: asociadas al deseo y la memoria y usadas como terapia, se encuentran en el complejo universo metafórico que rodea a los personajes de Jarman en The Last of England (1987) o The Garden (1990).

Este cine de la nostalgia, cine lírico, encuentra en The Angelic Conversation un importante jalón. La película es parte de una trilogía, junto a The Tempest y Jubilee, que se atreven con la construcción nostálgica con dos pilares del renacimiento inglés, Shakespeare y la reina Elisabeth. Las tres se refieren a la figura de John Dee, matemático, astrónomo, alquimista de la época isabelina. The Angelic Conversation está basada en los sonetos que Shakespeare parece que escribió a un joven, sobre los que se alza un complejo juego intelectual y sensorial de imágenes con variadas referencias históricas y culturales, a modo de ensayo visual cercano a las prácticas videoartísticas y del cine experimental y underground. En Jubilee, los espejos son usados narrativamente como un dispositivo para transmitir conocimientos. La cataptromancia (el uso de espejos) fue uno de los métodos de adivinación más populares en el siglo XVI.

Por su parte, Blue (1993) es una experiencia artística extrema, en la que fondo y forma fílmica se dan la mano para expresar la aceptación de su invisibilidad como homosexual. La película se compone de una banda icónica en completo azul sobre la que una voice over describe diversos episodios: durante su estancia hospitalaria a consecuencia de su contagio del VIH, 
relata sus vivencias íntimas con amigos y familiares, mientras se queda ciego. En el final de sus días, el autor niega la experiencia visiva y se vuelca en el sonido como medio de conexión con el mundo:

\begin{abstract}
«La rabia del feroz virus. Yo no tengo ahora que no hayan muerto o estén moribundo. Como si se tratase de una helada azul que los atrapó. En el trabajo, en el cine, en las marchas y las playas. En las iglesias de rodillas, corriendo, volando, callados o gritando.

(...)

La imagen es una prisión del alma, de su herencia, su educación, sus vicios y sus aspiraciones, sus cualidades, su mundo psicológico» (Voice over de Blue, 1993).
\end{abstract}

Su muerte a causa del sida en 1993, supuso una terrible pérdida.

\section{Pasolini: mirada y subjetividad}

La obra cinematográfica de Pier Paolo Pasolini (Bolonia, Italia, 1922) constituye un caso aparte y extremadamente singular en la historia del cine, ya que enlaza la vanguardia histórica con el cine social, hermanamiento sustentado por unas profundas convicciones éticas y estéticas sobre las posibilidades del séptimo arte.

El cine para Pasolini era un fenómeno irracional, contenido de sueños y memoria, que se conforma en lengua, en palabra, que puede combatir las bases del mundo racionalista occidental. El carácter subjetivo y subversivo y, a pesar de todo, concreto del cine, lo relaciona con la poesía; en ello se encuentra el fundamento de la concepción del mismo como lengua y la clave para entender su poder ideológico.

Pasolini empleó la temática homosexual en su cine con objetivos subversivos, como antonimia al ideal de vida burguesa. Como comunista, ateo y gay declarado, las relaciones y personajes homosexuales le sirvieron como representación de fórmulas de libertad privada que podían y debían ser orientativas de la deseada lucha de clases. La tendencia a la revisitación de temas clásicos y de la literatura y el arte italianos de la edad media y el renacimiento, hacen poder considerar a Pasolini un clásico de la modernidad cinematográfica. El particular universo temático e iconográfico del creador italiano se caracterizó por una profunda coherencia estética y ética basada en el humanismo y las tradiciones míticas.

En su Trilogía de la vida, compuesta por El Decameron (1971), Los cuentos de Canterbury (1972) y Las mil y una noches (1974), adaptó textos de la tradición clásica latina, utilizando el erotismo como instrumento para representar los vínculos entre fascismo y dominación. El profundo compromiso ético dejó huella en la sociedad italiana del momento. Por su parte, Medea (1970) retoma la historia de la tragedia de Eurípides para proporcionar una peculiar visión sobre la trasgresión sexual y la imposibilidad de conciliar modernidad y tradición. En ella muchos críticos han querido observar una reflexión del director sobre la pasión, como elemento unido con el sentimiento religioso: en Medea, la homosexualidad, amor trasgresor, desemboca en poder liberador, convirtiéndose en otro ejemplo que demuestra que "la sexualidad de Pasolini sirve fundamentalmente para salir de la categoría, no para volver de nuevo a unas etiquetas" (Scarpetta, 1985: 159.) 
Esta función se resuelve lingüísticamente "en la mirada de la cámara, en su tendencia a acariciar detenidamente los cuerpos y los rostros de los jóvenes" (Mariniello, 1999:, 297), recurso que se encuentra dentro de la idea pasoliniana de plano subjetivo indirecto, que permite la fusión del punto de vista del autor con el del personaje por arte de la cámara (dada la imposibilidad de que el director hable la lengua -el dialecto- del personaje, como haría un escritor) dando lugar a una especie de monólogo interior.

«Un personaje actúa sobre la pantalla y se supone que ve el mundo de una cierta manera. Pero al mismo tiempo la cámara lo ve, y ve su mundo, desde otro punto de vista, que piensa, refleja y transforma el punto de vista del personaje. Pasolini dice: el autor "ha reemplazado en bloque la visión de mundo de un neurótico por su propia visión delirante de esteticismo". Está bien, en efecto, que el personaje sea neurótico, para indicar mejor el difícil nacimiento de un sujeto en el mundo. Pero la cámara no ofrece simplemente la visión del personaje y de su mundo, ella impone otra visión en la cual la primera se transforma y se refleja. Este desdoblamiento es lo que Pasolini llama una "subjetiva indirecta libre» (Deleuze, 1994: 113).

A través del plano indirecto libre el cine alcanza una forma de superar la dualidad objetividad/subjetividad que constituye su naturaleza, que para Deleuze es una "forma estética superior":

«Se trata de superar la subjetivo y lo objetivo hacia una forma pura que se erija en visión autónoma del contenido. Ya no nos encontramos ante unas imágenes objetivas o subjetivas; estamos apresados en una correlación entre una imagen-percepción y una concien- cia-cámara que la transforma» (Deleuze, 1994: 113). Como figura intelectual resuelta a no dejarse encasillar, revistió el concepto materialista de historia, en lo de que evolución y progreso se refiere, con matices procedentes del mito y el pensamiento arcaico, influencia de su gusto por las civilizaciones prehistóricas. Este deseo se afirma en la obra de Pasolini sobre una cierta idea de nostalgia, en forma de comunión entre todos los momentos históricos, y de paralelismo pasado-presente-futuro, herencia de los planteamientos de Holderlin, Nietzsche o Leopardi. En este sentido, puede observarse, por ejemplo, una voluntad de convivencia entre culturas, espacios y tiempos a través de la vestimenta particularmente, pero también de la música y otros componentes estilísticos y de puesta en escena, que transporta la historia narrada hacia un nuevo nivel de opacidad.

«Aquí la indumentaria ya no es en absoluto antigua: Pasolini ha querido mezclar, sobre todo, la cultura africana primitiva, la antigüedad sumeria y la tradición azteca; todo ello en un escenario magrebí (Marruecos), al ritmo de cantos rumanos, árabes y japoneses. Se trata, por tanto, de lo que él considera una "prehistoria" totalmente caprichosa -en el sentido más pleno de la palabra- y onírica» (Joubert-Laurencin, 1995: 221).

En Jarman y Pasolini, puede comprobarse un intento de sublimar su experiencia vital homosexual con una función doble: de resistencia, de subversión, por un lado; profundamente al servicio fraterno de todos sus semejantes, por otro.

Ambos directores esbozan una alternativa, coherente en lo estético y lo ético, al programa ideológico dominante: concepción del arte como exploración de lo 
no dicho en las ideologías oficiales y revaloración de su capacidad de escándalo y desviación social; vuelta a los antiguos parámetros preburgueses y de épocas remotas liberadas de convencionalismos sociales en torno a los afectos -la Grecia Antigua, el Renacimiento, la época isabelina-; establecimiento de un lenguaje del cuerpo como ente singular, que resiste a la uniformidad social; fe en creencias pasadas y en la memoria como forma de recomposición de la historia en una conexión transtemporal pasado-presente-futuro... Todo este cúmulo de opciones éticas los vincula fuertemente dentro de una línea poco transitada de artistas -Jean Genet, Jean Cocteau son algunos otros...- que no se conformaron con una trasposición temática de su experiencia como homosexuales a sus obras: más allá, cristalizaron una forma de trascendencia histórica en sus personajes, escenas, acciones, que puede denominarse cercano a la elegía que hay detrás de toda nostalgia.

\section{Referencias}

Deleuze, G. (1994). La imagen-movimiento. Estudios sobre el cine, vol. 1. Barcelona: Paidós.

Dillon, S. (2004). Derek Jarman and Lyric film: the mirror and the sea. Austin: University of Texas Press. Greene, N. (1990). Pier Paolo Pasolini. Cinema as Heresy. Princeton/Nueva Jersey: Princeton University
Press.

Hanson, Ellis (Ed.) (1999). Out Takes: Essays on Queer theory and film. Duke of University Press.

Jarman, D. (1992). At Your Own Risk: A Saint's Testament. Londres: Hutchinson.

Joubert-Laurencin, H. (1995). Pasolini. Portrait du poète en cinéaste. París: Cahiers du Cinéma.

Mariniello, S. (1999). Pier Paolo Pasolini. Madrid: Cátedra.

Meyler, M. Q. “Opposing Heterosoc: Jarman's Counter-Hegemonic Activism", en Lippard, C. (1996). By Angels Driven: the films of Derek Jarman, ed. Chis Lippard, Londres: Greenwood Press.

Pasolini, P.P. (1981). El caos. Contra el terror. Barcelona: Grijalbo,

Pasolini, P.P. (1978). Escritos corsarios. Barcelona: Monte Ávila Editores,

Pasolini, P.P. (1972). Empirismo erético. Milán: Garzanti.

Peake, T. (2000). Derek Jarman: a biography. Nueva York: The Overlook Press.

Rodríguez, A. (2011). Nostalgia de la rosa: Elegía y añoranza en el cine de Derek Jarman. Tesis para obtener el grado de Maestría. Centro Universitario de Arquitectura, Arte y Diseño, Universidad de Guadalajara (México).

Scarpetta, G. (1985). L'impureté. París: Grasset.

Yates, F. A. (1966). The Art of Memoria. Chicago: University of Chicago Press. 
